\title{
ARTIGOS
}

\section{GÊNERO E CUIDADO EM POLÍTICAS: SALAS DE ACOLHIMENTO DO PROJOVEM URBANO}

MARY GARCIA CASTRO • MIRIAM ABRAMOVAY

\section{RESUMO}

O artigo analisa uma política de inclusão social, a saber, as Salas de Acolhimento e sua relação com o Projovem Urbano (Programa Nacional de Inclusão de Jovens). Discutimos que tal política remete ao debate contemporâneo sobre a economia do cuidar, em especial quanto à recorrência a uma força de trabalho feminina a baixo custo, que mobilizaria afetos e serviços similares aos domésticos, ou seja, "trabalho de mulher", mas com singularidades próprias, já que envolve também preocupações com profissionalização, via educação infantil. O presente estudo baseia-se em pesquisas realizadas em 15 municípios brasileiros, entre 2013 e 2015, sobre as Salas de Acolhimento, que atendem a crianças de zero a oito anos, filhos de jovens estudantes do Projovem Urbano, facilitando sua participação nesse programa. Conjugam-se análises empíricas com debates contemporâneos sobre economia do cuidar e gênero.

POLÍTICAS PÚBLICAS • CUIDADOS COM A CRIANÇA • PROJOVEM URBANO • INCLUSÃO SOCIAL

\section{GENDER AND CARE IN SOCIAL INCLUSION POLICIES: WELCOME ROOMS OF THE URBAN PROJOVEM PROJECT}

\section{ABSTRACT}

This article analyzes a social inclusion policy, the Welcome Rooms policy, and its relationship with the Urban Projovem program (National Youth inclusion program). Such a policy refers back to the present debate on the care economy, particularly as regards the participation of cheap female workforce that would involve affects and services akin to domestic ones, dubbed as "women's work, albeit with specific characteristics since it also involves the issue of professionalization via children's education. This study is based on research undertaken in 15 Brazilian municipalities, between 2013 and 2015, which deals with Welcome Rooms for the children (aged 0 to 8) of the Urban Projovem students, in order to facilitate their participation in the program. It combines empirical analysis and the current discussions on care economy and gender. 


\section{GENRE ET CARE DANS LES POLITIQUES D'INCLUSION SOCIALE: SALLES D'ACCUEIL DO PROJOVEM URBANO}

RÉSUMÉ

Cet article analyse la politique d'inclusion sociale des Salles d'Accueil et son rapport avec le Projovem Urbano [Programa Nacional de Inclusão de Jovens]. Cette politique remet au débat contemporain sur l'économie du care, surtout en ce qui concerne le récours à une main d'oeuvre féminine à bas coût qui mobilise des affects et des services semblables aux services domestiques, c'est à dire un "travail de femmes" avec des specificités puis qu'il comprend un souci avec la professionalisation par moyen de l'éducation des enfants. Cette étude se base sur des recherches entreprises dans 15 communes brésiliennes, entre 2013 et 2015, concernant les Salles d'Accueil qui desservent les enfants agés de 0 à 8 ans des jeunes étudiants du Projovem Urbano a fin dé faciliter la participation de ces derniers dans le programme. Ce travail articule analyses empiriques et débats contemporains sur l'économie de care et de genre.

POLITIQUE PUBLIQUE • SOINS À L'ENFANT • PROJOVEM URBANO • L'INCLUSION SOCIALE

\section{GÉNERO Y CUIDADO EN POLÍTICAS: SALAS DE ACOGIDA DEL PROJOVEM URBANO}

RESUMEN

El artículo analiza una política de inclusión social, a saber, las Salas de Acogida y su relación con el Projovem Urbano (Programa nacional de Inclusión de Jóvenes). Discutimos que tal política remite al debate contemporáneo sobre la economía del cuidar, en especial en lo que se refiere a la recurrencia a una fuerza de trabajo femenina de bajo costo, que movilizaría afectos y servicios similares a los domésticos, es decir, "trabajo de mujer", pero con singularidades propias, ya que también implica preocupaciones con profesionalización, vía educación infantil. El presente estudio se basa en investigaciones realizadas en 15 municipios brasileños, entre el 2013 y el 2015, sobre las Salas de Acogida, que atienden a niños de 0 a 8 años, hijos de jóvenes estudiantes del Projovem Urbano, facilitando su participación en dicho programa. Se conjugan análisis empíricos con debates contemporáneos sobre la economía del cuidar y género. 
NÁLISES SOBRE PROGRAMAS E POLÍTICAS DE INCLUSÃO SOCIAL SÃO IMPORTANTES prestações de conta ao público quanto a ações governamentais e formas de socializar experiências. É essa a pretensão do presente artigo, que se baseia em pesquisas realizadas em diferentes municípios do Brasil, entre 2013 e 2015, sobre o empreendimento governamental conhecido como Salas de Acolhimento, que atendem crianças de zero a oito anos, filhos de jovens estudantes do Projovem Urbano, ${ }^{1}$ facilitando sua participação nesse programa.

Defende-se que tal empreendimento traz marcas de gênero a serem destacadas, tais como a recorrência pública do cuidar e a possibilidade de mães de estratos na pobreza voltarem a estudar.

Considerando que cuidar envolve proteção, conjugam-se análises empíricas com debates contemporâneos sobre economia do cuidar, mas questionando a pertinência dessa literatura para o caso das Salas de Acolhimento, pois, embora tais estudos destaquem gênero, estariam mais voltados para o care, ou seja, o cuidado de idosos por migrantes em outros países, como França e Japão (GUIMARÃES; HIRATA; SUGITA,

O Programa Nacional de Inclusão de Jovens Projovem - foi concebido em 2005. Em 2008 passou a ter quatro modalidades sendo uma delas o Projovem Urbano, com a finalidade de atender jovens de 18 a 29 anos que não completaram o ensino fundamental.
2011; HIRATA, 2014; HIRATA; GUIMARÃES, 2012), para cuidados no campo da enfermagem (MEYER, 2001), ou para a legitimidade, como trabalho, das atividades domésticas (TORN, 2008).

Para um olhar sobre as Salas, é necessário combinar a perspectiva de gênero, o debate sobre o cuidar e a busca de uma identidade profissional pelas cuidadoras nas Salas, que ressaltam a importância de 
serem reconhecidas como educadoras infantis com orientação para uma educação lúdica, que combine, para a criança, tempo de brincar, de ser protegida, socialização e sociabilidade.

A seguir, as Salas de Acolhimento são discutidas enquanto uma política social e apresenta-se a metodologia empregada na pesquisa empírica desenvolvida em distintos municípios do Brasil em 2013-2015. Posteriormente, debate-se sobre acompanhamento, cuidado e gênero, entrelaçando referências à literatura com depoimentos colhidos no estudo de caso sobre as Salas, o que é feito também em análises sobre educação lúdica e inclusiva, juventude do Projovem Urbano, destacando gênero, as múltiplas nuances do cuidar e do acompanhamento nas Salas, bem como o sentido das Salas na relação mães e filhos e como profissão, para as cuidadoras.

\section{AS SALAS DE ACOLHIMENTO COMO POLÍTICA SOCIAL}

Implantadas em 2012, as Salas de Acolhimento se apresentam como uma resposta à demanda recorrente dos principais atores do Projovem Urbano (alunos, professores e coordenadores). Essa demanda recebeu destaque durante a $2^{\text {a }}$ Conferência Nacional de Juventude, que aconteceu em dezembro de 2011, na qual uma das propostas direcionadas à área de educação envolvia a criação e ampliação do número de creches voltadas para os filhos de jovens e adolescentes que precisam retomar os estudos, proporcionando às crianças "condições de segurança e bem-estar enquanto seus responsáveis frequentam as aulas” (BRASIL, 2012b).

A gestão das Salas de Acolhimento envolve várias instâncias, como: o Ministério da Educação/Secretaria de Educação Continuada, Alfabetização, Diversidade e Inclusão - MEC/Secadi -, que coordena o Projovem Urbano; secretarias municipais ou estaduais de Educação; a direção das escolas onde estão os núcleos do Programa; o corpo de professores do Projovem Urbano; e as cuidadoras ou educadoras das salas, a grande maioria mulheres com pelo menos o ensino médio.

\section{NOTAS METODOLÓGICAS}

$O$ estudo de caso permite formatar uma pesquisa, a partir de uma pequena amostra, seguindo alguns pressupostos teóricos iniciais, mas mantendo-se atento a novos elementos emergentes e importantes para discutir a problemática em questão.

\footnotetext{
O estudo de caso é uma inquirição empírica que investiga um fenômeno contemporâneo dentro de um contexto da vida real, quando a fronteira entre o fenômeno e o contexto não é claramente evidente e onde múltiplas fontes de evidência são utilizadas. (YIN, 2010, p. 23)
} 
Considerando as reflexões de Yin (2010), em 2013 desenvolvemos estudo de caso sobre as Salas de Acolhimento, em que enfatizamos a importância de um olhar que se filtra por referências teóricas conceituais sobre economia do cuidar e sua associação com o lúdico, a garantia do tempo de brincar, de ser feliz e protegido, em se tratando de crianças pobres, vitimizadas por vulnerabilidades sociais, assim como suas mães e pais, os jovens do Projovem Urbano.

Como estudo de casos múltiplos, não são comparados lugares, núcleos, Salas em distintos municípios, mas há parâmetros como campo em que se pinçam fatores que são destacados por entrevistados e que melhor se enquadram ao que as normas sobre as Salas recomendam que estejam mais afins ao que se espera com os conceitos de cuidar, ou seja, proteger, propiciar momentos lúdicos que colaborem para uma socialização que vá contra estereótipos de gênero, orientações por competição e discriminações várias. Em 2013, foram realizados entrevistas, grupos focais e observação em núcleos do Projovem Urbano da edição de 2012, ouvindo educadoras em Salas de Acolhimento, alunos do Projovem Urbano e gestores no campo de educação nos seguintes municípios: Feira de Santana (Bahia); Rio de Janeiro (Rio de Janeiro); Quixeramobim, Mombaça, Iguatu (Ceará); e Rio Branco (Acre). No total foram cerca de 14 entrevistas com as educadoras responsáveis pelas Salas de Acolhimento e 12 grupos focais, envolvendo uma média de oito pessoas por grupo de jovens do Projovem Urbano.

Em 2014/2015, tendo como referência núcleos do Projovem Urbano da edição de 2013, ampliou-se a pesquisa em João Pessoa (Paraíba), Belém (Pará), Campo Grande (Mato Grosso do Sul), Nova Iguaçu (Rio de Janeiro) e Curitiba (Paraná). ${ }^{2}$

Sob diferentes ângulos do trinômio Sala de Acolhimento/Projovem Urbano/escola, foram abordados distintos personagens e seus papéis. De fato, olhar a Sala, a mãe ou o pai da criança e a educadora, entre outros, é ao mesmo tempo olhar o outro personagem, olhar para si mesmo e o cenário de contexto, questionando a construção do outro por seus parâmetros. Tal jogo de percepções colaborou para qualificar perfis dos distintos atores, considerando atividades desenvolvidas, a partir de técnicas qualitativas.

As autoras elaboraram para o MEC/Secadi "Documentos técnicos" contendo análise das informações quantitativas e qualitativas sobre os núcleos, os educadores e as crianças atendidas nas Salas de Acolhimento e diagnósticos das boas práticas de gestão. Relatórios não publicados.

\section{ACOLHIMENTO, CUIDADO E GÊNERO}

As Salas de Acolhimento colaboram para o resgate do direito à educação dos jovens do Projovem Urbano que não têm com quem deixar seus filhos quando frequentam as aulas. Contudo, diferentemente do modelo de creche tradicional e se afastando da ideia de apenas, o que já seria muito, prover um lugar para guardar as crianças enquanto os pais e mães estudam, as Salas recorrem aos vocábulos nativos "acolhimento" 
e "cuidado", comum nas entrevistas com as educadoras, ou seja, as responsáveis pelo cuidado das crianças.

De fato, a crescente literatura hoje sobre economia do cuidado, relacionada a serviços e programas baseados em atendimentos pessoais, singulariza tal economia, pelo fato de que, além de contribuir para ganhos sociais e individuais, requer também a combinação de qualidades objetivas e subjetivas, mobilizando emoções, "trabalho material e técnico” e sentido de justiça social. Zelizer (2012, p. 18) também enfatiza que a economia de cuidados (care) "Inclui qualquer tipo de atenção pessoal, constante e/ou intensa, que visa a melhorar o bem-estar daquele ou daquela que é o objeto".

Contudo, os debates mais contemporâneos sobre economia do cuidar, ou melhor, do care decolam, como antes frisado, em sua maioria, de estudos sobre cuidado de idosos por parte de mulheres migrantes, geralmente sem exigências de escolaridade, ou no campo da enfermagem e do serviço e trabalho doméstico. Mas, enquanto o termo cuidar não seria novo, segundo pesquisa realizada por Guimarães (2016), o de cuidadora, como atividade no mercado relacionada aos "cuidados com humanos", seria mais recorrente na imprensa somente a partir de 1990, e com chamadas relativas tanto a homens como a mulheres cuidadores, geralmente, de idosos. Guimarães (2016) pesquisou como tais vocábulos - cuidado e cuidador/a - aparecem no jornal $O$ Estado de $S$. Paulo, entre o final do século XIX (1875) e início do XXI (2014).

Guimarães (2016, p. 75) reflete que o cuidar, pelo fato de transitar entre o mercado e o "amor", para muitas feministas, deveria se libertar do que seria a "sua figura fundante", ou seja, "o amor materno". A autora nos sugere que a controvérsia sobre dissociação entre investimentos emocionais e formas mercantis do cuidado não interessaria somente às feministas, sendo resgatada pelos "processos de mercantilização”. Não é esse o caso dos cuidados de crianças que focalizamos nas Salas. São tênues as fronteiras entre o fazer com amor e a demanda por reconhecimento como profissional, e muitas cuidadoras nas Salas frisam que gostam e fazem com amor seu trabalho, mas não o querem desvalorizado profissionalmente, embora muitas se orgulhem de que seria um trabalho mais bem exercido por mulheres.

O papel da afetividade é um tema que vem sendo discutido dentro da problemática mais ampla dos valores e que, na equação gênero e família, traz complicadores para os nortes de mudanças e simetria de relações (GIDDENS, 1993). Vale ainda mencionar os ensaios sobre o valor da afetividade enquanto bem de consumo (commodity), como nas contribuições de Illouz (2008), considerando trabalhos de Foucault, Bourdieu e Giddens - ou seja, focalizando a afetividade não apenas como dimensão do privado, mas também condicionada ao público. 
Autores do campo do conhecimento psi destacam também, no cuidar da criança, a ética de responsabilidade, como, por exemplo, Figueiredo (2009, p. 133):

\begin{abstract}
Chamaremos de ética a esta dimensão da disposição do mundo humano em receber seus novos membros; nela as operações de separação e ligação - corte e costura - tão decisivas no fazer sentido [...] se manifestam de forma tão ou mais cristalina, posto que menos rígida [...] Tal dimensão inclui, naturalmente, o que cabe na rubrica das práticas de 'educação', mas não se reduz a isso, ao menos no sentido restrito do termo. Experiências que não costumamos entender como alvo de uma 'educação' também são motivo de cuidados, como as que dizem respeito ao prazer, ao divertimento, às brincadeiras e entretenimentos, por exemplo.
\end{abstract}

Mas a responsabilidade dos adultos para com as crianças, quer no âmbito da família quer quando se realiza em instituições, tende a se alinhar por gênero, sendo socialmente mais enfatizado o amor materno e insistindo-se na ética da mulher para com o outro, a outra.

Mudanças no mundo do trabalho vêm contribuindo para o trânsito entre o trabalho e o não trabalho ou o apelo para qualificações tidas como privadas ou próprias das culturas de gênero pela esfera do público, do mercado. Assim, o crescimento da economia do cuidar, no mundo público, parte do setor de serviços como enfermagem, atenção à infância, docência e trabalho doméstico remunerado via empresas ou pessoal. O cuidado de idosos ou doentes em casa (home care) viria apelando para o que tradicionalmente seriam qualidades femininas, como o apelo ao emocional, à ética de responsabilidade com o outro, sem necessariamente tal valorização ter como equivalência a valorização monetária nas relações de compra e venda da força de trabalho.

Segundo Soares (2012, p. 55), “O trabalho emocional é crucial para o cuidar. E é perpassado por múltiplas relações sociais de outras ordens e por outras dimensões implicadas nesse trabalho. É preciso retirar da invisibilidade esse componente do trabalho de cuidar".

A transferência do cuidar do privado para o público, por meio de políticas sociais como as Salas de Acolhimento, por um lado, colabora para desestabilizar a reclusão das mulheres ao plano do doméstico, já que são transferidos para instituições públicas os cuidados das crianças, permitindo que as mães possam estudar, mas, por outro, pode reproduzir estereótipos de gênero, se, como reclamam as cuidadoras nas Salas, lhes negam oportunidades de profissionalização, reciclagem e aprofundamento sobre educação infantil apropriadas para o trabalho nas Salas.

Tradicionalmente, às mulheres tem sido confiado o cuidado às crianças e é com certa dificuldade que conseguem voltar a estudar e 
mesmo a trabalhar, muito embora possam ser encontrados casos em que os homens tomam para si o papel no cuidado com os filhos. As Salas de Acolhimento surgem para responder à demanda dessas jovens mães que não têm com quem deixar seus filhos para frequentar a escola.

O tema dos cuidados destinados à criança não pode estar dissociado da problemática das transformações que a família vem sofrendo nas últimas décadas. As formas de investimento de cada membro da família no acompanhamento do desenvolvimento das crianças estão inevitavelmente relacionadas a mudanças e valores sociais estruturalmente construídos, como aumento da participação feminina no mercado de trabalho e ampliação dos direitos da mulher como sujeito nas esferas públicas e privadas, como, por exemplo, o direito a estudar, bem como à demanda por equipamentos e políticas sociais que colaborem em uma rede de apoio aos pais e mães no que diz respeito ao cuidado das crianças. ${ }^{3}$

Hirata e Guimarães (2012), em estudo sobre cuidado e educadoras, destacam que cuidado é conceito que envolve atenção ao outro e solicitude, devendo ser retirado do âmbito do privado e do pessoal e, principalmente, do entendimento comum de que cuidado é uma qualidade "inata e natural das mulheres”, pois trata-se de construto básico de justiça social. Ou seja, cuidar mobiliza afetividade e vínculos, além de proteção e atenção ao outro, à outra, que, no caso das Salas de Acolhimento, são crianças, pais e mães em situações de vulnerabilidade social.

A relação entre acolher e cuidar pede olhar crítico, o que discutimos após algumas referências à propriedade do conceito de acolhimento quando o foco são as Salas.

Em estudo de caso pioneiro sobre Salas de Acolhimento no Rio de Janeiro, Gonçalves da Fonseca (2014) ressalta os indicadores que comumente são acionados em relação ao conceito de acolhimento, tendo como referência o filósofo francês Jacques Derrida (2004 4 apud GONÇALVES DA FONSECA, 2014) para quem cuidar teria o sentido de oferecer hospitalidade ao outro:

\begin{abstract}
A palavra "hospitalidade" vem aqui traduzir, levar adiante, reproduzir as duas palavras que a precederam: "atenção" e "acolhimento". Uma paráfrase interna, também uma espécie de perífrase, uma série de metonímias expressam a hospitalidade, o rosto, o acolhimento: tensão em direção ao outro, intenção atenta, atenção intencional, sim ao outro. (DERRIDA, 2004, p. 40 apud GONÇALVES DA FONSECA, 2014, p. 81)
\end{abstract}

Note-se que, antes das Salas de Acolhimento, não havia no Projovem Urbano espaço nem serviço orientado para o atendimento dos filhos dos estudantes, cabendo, por ação espontânea, aos colegas cuidarem dos mesmos. Segundo Gonçalves da Fonseca (2014, p. 82), configurações da família e conquistas das mulheres no campo das relações de gênero, ver entre outros, Giddens (1993), Castro, Carvalho e Moreira (2012), Samara (2002), Moraes (2001) e Jelin (2006).

4 DERRIDA, Jacques. Adeus a Emmanuel Lévinas. Tradução de Fábio Landa, colaboração de Eva Landa. São Paulo: Perspectiva, 2004. 
"Muitas dessas crianças frequentavam as salas de aula, corredores e refeitórios sem que houvessem condições adequadas de proteção, conforto e segurança”.

A autora cita documento do Ministério da Saúde, intitulado “Acolhimento nas práticas de produção de saúde”, em que se explicita que "acolher significa dar abrigo, aceitar, escutar, atender, receber e admitir o outro”, e ressalta que mais do que uma boa ação, ou qualidade, há no acolhimento uma intencionalidade de ações.

$\mathrm{O}$ ato de educar está conectado ao ato de cuidar. Os primeiros momentos do aluno na escola ou cada nova etapa escolar precisam ser planejados de forma a proporcionar conforto, cuidados e segurança, seja ao aluno, criança ou adulto:

Considerar a adaptação sob o aspecto de acolher, aconchegar, procurar, oferecer bem-estar, conforto físico e emocional, amparar, amplia significativamente o papel e a responsabilidade da instituição de educação neste processo. A qualidade do acolhimento deve garantir a qualidade da adaptação; portanto trata-se de uma decisão institucional, pois há uma inter-relação entre os movimentos da criança e da instituição fazendo parte do mesmo processo. (GONÇALVES DA FONSECA, 2014, p. 84)

Contudo, acolher e cuidar de crianças muitas vezes escorrega em tutela, imposição de valores, educar de acordo com concepções próprias do que se entende por educação, o que em tempos de expansão da ênfase em evangelização pode derivar em confusão entre educação laica e religiosa, "ensinar" valores religiosos, impor credos às crianças que, por sua idade, não teriam condições de crítica. É quando proteção pode significar doutrinação.

Nas Salas de Acolhimento se segue um modelo singular de cuidado compartido, pois, se as educadoras ficam com as crianças enquanto os responsáveis estudam, estes muitas vezes fazem suas merendas e refeições junto com as crianças. Em princípio as escolas onde se encontram os núcleos do Projovem Urbano deveriam, segundo as normas das Salas, ser responsáveis pelo tipo de alimento dado às crianças. Com tal modelagem recodifica-se o que se entende por cuidar/acolher, evitando a separação de espaços afetivos e contribuindo para uma socialização mais fluida das crianças com o mundo público, uma escola.

A contribuição voluntária, por querer, em alguns casos por necessidade do trabalho de cuidar, é uma marca que bem ilustra o lugar do afeto nessa relação que mescla trabalho, ética e sensibilidade para com a criança cuidada: 
As caixas estão lá na Sala. Eu trouxe muitos brinquedos. Sobras da outra escola lá que eu trabalho, eu fui trazendo. Tem boneca, tem carrinho, tem brinquedo de montar, tem peça de encaixe. Tem muita coisa de brinquedos que a gente conseguiu. Tem uns brinquedos também que a gente fez na Sala com eles. Fizemos jogo da velha, fizemos dama com tampinha de garrafa PET. Fizemos jogo da memória, fizemos algumas coisas com eles na Sala. Durante a noite a gente ia dividindo os momentos. Um momento era com os brinquedos. Um momento a gente sentava para fazer esses jogos. (Entrevista com educadora em núcleo do Projovem Urbano, Feira de Santana)

Note-se também que pode haver diversos tipos de cuidados, já que após a seleção as educadoras, ainda que discutam entre si e com coordenadores o planejamento da semana, não se atualizam ou têm acesso a literatura diversificada sobre cuidado de crianças em termos de educação lúdica e inclusiva, tema que é abordado a seguir.

\section{EDUCAÇÃO LÚDICA E INCLUSIVA}

A cultura lúdica, o brincar, é considerada por vários profissionais no campo da educação infantil, sociologia da infância e psicologia desenvolvimentista, basicamente, um direito que imprime marcas de socialização e sociabilidade, visões de mundo, mas que não deveria ter tais dimensões como suficientes. Cuidar e acolher sugerem garantir direito à cultura lúdica, providenciando espaço, recursos e proteção sem limitar autonomia e descobertas. O interesse em relação ao ensino infantil se baseia no reconhecimento de que essa é uma fase importante de estruturação do ser e, principalmente, do estar na sociedade, mas que a criança tem referentes culturais e históricos e precisa ser mais compreendida em sua integridade, e não ser objeto de socializações "autocráticas”. Segundo Lapa Santo e Panizzolo (2013, p. 82):

\footnotetext{
As pesquisas com crianças têm aumentado nas últimas décadas. Pode-se constatar que a criança tem ganhado um lugar diferenciado nos estudos sobre a infância. Educadores e pesquisadores da área da Educação Infantil procuram compreender cada vez mais as temáticas de estudos que tangem a faixa etária de $\mathrm{O}$ a 5 anos, trabalhando com práticas de pesquisa que a tratam como sujeito, possibilitando conhecer a infância nas várias formas de ser criança. $\bigcirc$ crescente interesse tem levado pesquisadores e educadores a buscar teóricos que tratam a criança como um ser cultural, social e histórico, como apontam Alderson (2005), Montandon (2005), Muller (2005), Corsaro (2005), Sarmento (2005), Bouvier (2005) e Sirota (2005).
} 
De acordo com documentos do MEC/Secadi sobre as Salas e entrevistas com atores e atrizes de escalões variados, relacionados à gestão das Salas, se tem claro que essas devem ser lugar prazeroso para as crianças e que brincar e ser protegido são dimensões básicas do Programa, sem ter educação escolar como vetor.

De fato, mesmo no campo de educação infantil há ambiguidades sobre o que se entende por brincar: "Há educadores que valorizam a socialização, adotam o brincar livre, e os que visam a escolarização ou aquisição de conteúdos escolares, o brincar dirigido e os jogos educativos" (KISHIMOTO, 2001, p. 230).

Para alguns, o brincar seria parte de um processo com objetivos de educar em um modelo de processo de amadurecimento, como o que reproduz divisões sexuais, papéis de ser menina e de ser menino e inserção em valores, inclusive de ordem religiosa. Já para outros, considerando-se um direito da criança, o ser criança, brincar deveria ser garantido como espaço de criatividade, de buscas próprias. É quando o cuidar toma o sentido de proteger aquele direito e evitar "tutelagens", mesmo que bem-intencionadas. Kishimoto (2001, p. 229), referindo-se ao lugar dos brinquedos em escolas da rede de educação infantil, que pesquisou em São Paulo, chama a atenção para limitações de como se dá o brincar:

\begin{abstract}
Os resultados indicam que a educação infantil da rede pesquisada apresenta concepções de criança - destituídas de autonomia - e de educação infantil voltada para aquisição de conteúdos específicos. Os brinquedos e materiais pedagógicos mais significativos são os chamados educativos, materiais gráficos, de comunicação nas salas; e os de educação física, para o espaço externo. Brinquedos que estimulam o simbolismo e a socialização, como jogos de faz de conta, construção e socialização, aparecem com percentuais insignificantes, apontando o pouco valor da representação simbólica e do brincar.
\end{abstract}

Na equação cuidar-brincar agregar-se-ia, portanto, um elemento a mais ao sentido de proteção, uma vez que não somente o bem-estar físico da criança seria considerado, mas também a orientação para inclusão, sem didatismo. O estar junto, com outras crianças, sem reproduzir estereótipos de gênero e outros, assim como modelar um ambiente de convívio agradável, não é tarefa fácil, considerando-se que muitas das crianças convivem com violências de várias ordens e o projeto da Sala não é de reeducar, mas sim garantir um espaço lúdico, ainda que muitos pais e mães insistam que deveria ser, principalmente para as crianças com mais idade, espaço de reforço escolar.

Tal dilema por uma socialização diferenciada é enfrentado por educadoras, sendo que muitas apelam para estratégias pautadas na 
criação de vínculos e afetos, propiciando que as crianças por si identifiquem que há modelos diversificados e que se pode aprender brincando, sem que se sacrifique o brincar, em nome do escolarizar.

Considera-se que, na Sala de Acolhimento, as crianças "estão seguras”, já que estão com pessoas "que têm capacidade de cuidar” e "as mães se sentem seguras de deixar os filhos com a gente”, além do fato de elas estarem perto das crianças. As educadoras de Rio Branco informaram que, para a maioria das crianças tiradas das Salas, o motivo foi a saída dos pais do Projovem: “começaram 13 alunos e permanecem até hoje meus 13 alunos. Eles têm um carinho imenso, eles chegam a dizer para as mães que eu sou a melhor professora do mundo”.

Educadoras em Feira de Santana também se referem ao efeito pedagógico das Salas, o carinho que dão às crianças, influenciando mudanças no comportamento das mães.

É comum que tanto as crianças como seus pais e mães façam comparações entre a escola, quando as crianças a frequentam, e a Sala de Acolhimento, sendo que as crianças ressaltam mais a dimensão lúdica e recreativa da Sala:

As mães chegam até a dizer, assim, que o dia que elas não vão para a escola, e as crianças pra Sala de Acolhimento, elas [as crianças] ficam reclamando porque queria ir pra sala da tia, brincar com os coleguinhas, porque o ensino normal deles, a escola normal é diferente do Acolhimento. É lógico que lá ele tem que estudar, aprender, requer um esforço, lá no Acolhimento é uma coisa assim, muito à vontade, eles brincam, eles dançam, eles cantam, é diferente. A criança, ela quer brincar de coisas diversificadas, e no Projovem elas se encontram, porque desenham, pintam, ao mesmo tempo. Eu as deixo ir ao quadro, à lousa, escreverem com giz, ter um dia de professora. Eu gosto de brincar com eles, ai eles vão, escrevem com giz, então a gente diversifica vários tipos de atividade, o que na escola pública não pode. Inclusive eu não gosto de sentar com eles em fila, eu gosto em círculo. Ai cada um, um opta por um tipo de atividade, outro opta, não quer esse, então vamos pra esse, eu deixo eles escolherem o que realmente eles querem aprender.

É diferente, porque na sala de acolhimento você não passa você não dá aulas, você vai fazer entretenimento com aquelas crianças, dar uma atividade recreativa para elas. Isso diferencia. Raramente, quando a criança vem com uma atividade - "tia você me ajuda?" -, ai você ajuda se houver tempo. Porque no começo do programa as salas são superlotadas. No decorrer ou as mães encontram com quem deixar as crianças ou alguma delas desistem e fica um número menor e melhor de trabalhar. (Entrevistas com educadoras em núcleo do Projovem Urbano, Rio Branco) 
O poder brincar, ser criança, seria um dos atrativos que qualifica as Salas de Acolhimento, mas ressalta-se que é um brincar estimulado, que apela, em muitos casos, para jogos e diversos tipos de atividades:

Os de seis, sete anos sabem que vêm para cá fazer uma atividade recreativa, pintura, assistir filme, a gente passa filme duas vezes na semana. No dia que cai na sexta para passar esse filme, a gente faz um cine pipoca, faz pipoca e dá para eles. Têm as pinturas, jogos, pega varetas, dominó, são atividades recreativas. (Entrevista com educadora em núcleo do Projovem Urbano, Rio Branco)

As educadoras também destacam o brincar como um dos principais atrativos das Salas para as crianças, o que influencia para que muitas prefiram as Salas às escolas: "brincam o tempo todo"; "aqui eles brincam, lá na escola têm que estudar”.

Elas consideram que há combinações entre o brincar e o ensinar, mas frisam que acolher compreende cuidar e brincar, basicamente:

[Diferentemente da escola] aqui não tem compromisso, porque a professora está para ensinar, e aqui nós estamos aqui para tomar conta, para acolher. A gente acaba ensinando porque se ensina interagir, a dividir e compartilhar. E com as brincadeiras eles acabam aprendendo também, porque eles aprendem as cores, os números. Antigamente eles viviam ganhando no jogo da velha. (Entrevista com educadora em Núcleo do Projovem Urbano, Nova Iguaçu)

O brincar no caso das crianças mais velhas, principalmente os meninos, seria basicamente jogar bola, o que é facilitado quando na escola há um pátio, uma quadra ou um ginásio, equipamentos comuns nas escolas visitadas.

\section{JUVENTUDES DO PROJOVEM URBANO, DESTACANDO GÊNERO}

Os estudos sobre perfis de jovens brasileiros, em geral, apontam para situações que os vulnerabilizam socialmente, como pobreza e desemprego, agravadas por trajetórias escolares irregulares ou excludentes (DUARTE, 2009). Também verifica-se que a conciliação entre trabalho e escola, quando possível, ocorre em detrimento do processo de escolarização, ou seja, por fatores relacionados às condições de trabalho e/ou à exclusão educacional.

O percentual de mulheres matriculadas no Projovem Urbano em 2012 (61\%) é bem superior ao de homens (39\%), dado que reforça a tendência observada desde o início do programa em todo o Brasil, o que revela um atendimento expressivo do público feminino e evidencia que as mulheres abandonam mais a escola. Falar dos direitos à educação significa também falar dos direitos da mulher, sendo esse um compromisso 
do Estado no sentido de combater as discriminações e desigualdades sofridas pelo gênero feminino (NOVAES; CARA; MOREIRA, 2006).

Sobre o perfil dos jovens do Projovem Urbano, destaca-se que a maioria do público é feminina, sendo praticamente o dobro dos homens, com idade média de 23 anos. Em especial, constata-se que os mais jovens têm menos interesse em permanecer na escola, demonstrando pretensões mais imediatas por trabalho ou atividades de lazer.

As Salas de Acolhimento, insiste-se, têm o objetivo de atender ao público do Projovem Urbano, em sua maioria com filhos e sem ter com quem deixá-los para ir à escola, como revelam os dados da pesquisa com alunos egressos da $1^{\mathrm{a}}$ e $2^{\mathrm{a}}$ entrada (BRASIL, 2011b), indicando que $75 \%$ dos jovens matriculados tinham filhos, dos quais $82 \%$ eram mulheres. Embora a dificuldade de não ter com quem deixá-los atinja potencialmente a todos que têm filhos, no Programa, essa situação é predominante entre as mulheres (GONÇALVES DA FONSECA, 2014).

$\mathrm{Na}$ pesquisa, muitas das jovens declararam ter se arrependido de ter abandonado os estudos quando se casaram: "Foi o Projovem que deu uma nova oportunidade da gente começar de novo", reiterando: "Se arrependimento matasse".

Há também uma fantasia por parte dos maridos misturada a um temor de que as mulheres se tornem independentes deles, que possam trabalhar e levar suas próprias vidas, que tenham autonomia, o que causa ciúmes e mexe com a questão do machismo e da virilidade masculina, do ser provedor, como sublinha uma jovem: "É não só pelos colegas de sala. Eles têm medo da mulher ser independente e parar de depender deles, que eles acham que a gente tem que andar de baixo da sola do pé e não é! Nós temos que ser independentes”.

De fato, há consciência da insegurança masculina que leva a proibir que as mulheres circulem na esfera pública e, principalmente, se tornem independentes via trabalho:

\footnotetext{
É verdade. Porque tem homem que pensa que ela depende de mim e não tem como ela trabalhar. (Grupo focal de estudantes em núcleo do Projovem Urbano, Rio Branco)
}

Eu acho que não é ciúme não. Não é nem desconfiança. A pessoa não, ela acha que é assim, como se fosse para não crescer. Porque sabe que vai estudar e vai ser alguém na vida e aí não vai depender. Porque é assim, a gente vive com um homem e dependendo do homem se você comprar um palito de fósforo você tem que pedir a ele. Tem que dar satisfação. E a pessoa independente não vai pedir. Ai ele acha que pessoa está querendo ser mais do que ele. E ele porque é o homem tem que botar tudo dentro de casa. (Grupo focal de estudantes em núcleo do Projovem Urbano, Feira de Santana) 
A realidade comporta cada vez mais diversidade, ainda que a tendência seja a reprodução de assimetrias de gênero, com a subordinação da mulher em termos de abortar vontades por autonomia, mobilidade, querer crescer via escolaridade. É um caso único o da jovem que conta que sempre foi pressionada para estudar e que o marido até mesmo a humilhava por não estudar: "Eu era muito humilhada, meu marido só me humilhava dentro de casa me dizendo que eu só prestava para parir e hoje eu estudo e eles estão tudo sem estudar".

Um entrevistado, do sexo masculino, também ilustra uma exceção da tendência encontrada, já que afirma que sempre incentivou, sem se importar se a mulher quer estudar: "Eu não me importo não, se ela quer estudar, ela vai estudar. Mas ela não quer!”.

Exigir mais liberdade e ser dona de suas escolhas vem acompanhado da obrigação de proteger os filhos, pensando no futuro das crianças. A mãe assume o seu papel de gênero de responsável pelo presente e o futuro do filho. Não necessariamente tal codificação lhes tolhe; ao contrário, há casos em que a assunção de tal papel lhes impulsiona a querer crescer, alimenta expectativas, faz com que confiem mais em si: "Porque eu quero um futuro para os meus filhos. Quero poder ajudar os meus filhos, mas a minha vontade mesmo é estudar e conquistar um futuro para sustentar meus filhos".

Os depoimentos corroboram a importância de bandeira dos movimentos feministas: a dos direitos das mulheres à educação. No caso do Projovem Urbano, fica evidente a vontade dessas mulheres de alguma emancipação econômica e nas relações de gênero, tendo, portanto, a volta ao estudo sentido de resgate de dignidade.

Os testemunhos sobre violências domésticas e despotismo por parte do esposo são comuns em falas de jovens mulheres, sendo que muitas frisam terem deixado de estudar por ciúmes deles e, outras, que só voltaram a estudar depois que se separaram:

- Eu casei, aí o meu marido começou a ter muito ciúmes. É meio maluco, é meio pinéu ai ele falava que ia pra escola pra arrumar outra pessoa, e proibiu eu de estudar e ai depois eu tive filho, fiquei quatro anos casada com ele e depois tive filho, e eu não tinha com quem deixar, ai quando apareceu o Projovem que dava pra levar criança e deu pra vir, a maioria não volta porque não tem com quem deixar os filhos essa é a verdade.

- E o Projovem deu a oportunidade da gente estudar e trazer os nossos filhos.

Comigo foi quase a mesma coisa delas, eu parei de estudar por causa do meu ex-marido ele me proibia de estudar porque ele tinha muito ciúmes. Ele ia na sala de aula e fazia passar vergonha ai eu parei, ai fiquei um bom tempo sem estudar. 
- Ah eu me separei dele, por isso que eu voltei a estudar, esse meu marido não, ele não liga, mas o meu ex-marido ele ia na Escola, ele gritava, se tivesse alguém sentado do meu lado era ciúmes, tinha repressão.

- Homem acha que mulher é só pra lavar e passar roupa e cozinhar. E a coisa não está acontecendo mais. Ai vê a mulher crescendo, acha que vai ser mais que ele.

- A gente em casa somos dependente deles por causa dos filhos, e a mulher progredindo eles têm medo, entendeu? (Diálogo em grupo focal com jovens, em núcleo do Projovem Urbano, Nova Iguaçu)

Nos diálogos sobre a trajetória de vida escolar e o motivo do abandono, há destaque para uma gravidez, para o fato de que o companheiro não permitia estudar. Mas muitas mulheres, assim como os jovens, se referem a escolhas por outros atrativos, como o se divertir e até por preguiça e pelos amigos, ter que trabalhar, desânimo ou falta de poder de sedução da educação formal, da escola, diante de outros rumos ou não. Em tal trajetória, observa-se a ênfase no Projovem Urbano para se voltar a estudar e nas Salas de Acolhimento.

- Preguiça mesmo. [Risos].

- Eu parei de estudar por preguiça mesmo [...] e por má influência.

- Ah, os amigos, ah, "não vamos pra escola hoje não, vamos pro parque, vamos na pracinha, vamos ali tomar um tereré [...] nós vamos beber, vamos fazer alguma coisa parecida"... "Vamos pra feira". Tem bastante isso. [...] Teve uma época que eu fiquei duas semanas sem vir pra escola.

- Eu porque gostava muito de bagunça né eu sempre fui uma menina rebelde né, como diz minha mãe. Então eu gostava muito de bagunça, então eu achava que na escola era chato, que estava perdendo tempo. Isso aí. Minha mãe também não se interessou muito. Isso aí.

- Eu engravidei também. Tinha treze anos e quando tive minha filha só queria fazer bagunça, né? Quando ela nasceu ela chorava muito aí eu não pude mais estudar, porque como ela chorava muito. Ai quando ela fez um ano, eu me separei do pai dela, e ele achou que deixou de ser pai. Ai eu tive que trabalhar para poder cuidar dela. Ai só agora tive oportunidade de voltar. O Projovem começou e aí eu voltei a estudar.

- Eu também engravidei com 17 anos. Meu primeiro filho está com oito anos e o mais novo está com quatro anos. Ai comecei a trabalhar. Eu trabalhava fora, comecei com 17 anos e aí não voltei mais. Voltei agora pela oportunidade do Projovem, por causa do 
A importância das Salas de Acolhimento para as mães estaria tanto em permitir que uma norma de gênero se reproduza, sem escolhas seletivas por parte da mulher entre estudar e cuidar dos filhos, já que socialmente se espera que cabe à mulher cuidar dos filhos, o que é reforçado por imposições do marido nas relações de casal, como também em contribuir para alguma subversão da norma patriarcal de divisão de espaços entre homens e mulheres, ou seja, de menor circulação no público pela esposa. Contudo, tal subversão é lenta e enfrenta resistências por parte dos maridos, havendo, conforme relatos das educadoras, casos de violência doméstica pelo fato de as mulheres estarem estudando à noite:

Para as mães [a Sala de Acolhimento] é muito importante. Como muitas delas mesmo chegam a comentar, elas se sentem seguras e confiantes por saber que elas estão numa sala ao lado e os filhos estão pertinho, qualquer coisa, talvez nós não cheguemos a reso/ver, mas vai lá, chama a mãe. (Entrevista com educadora em núcleo do Projovem Urbano, Rio Branco)

Eu acho que a proposta [das Salas de Acolhimento] é muito boa. Porque a gente sabe que na realidade dessas pessoas que precisam voltar a estudar depois de certa idade, já tem uma vida que trabalham e que tem a oportunidade de voltar a estudar, mas tem que ser à noite e têm filhos, muitos não têm realmente com quem deixar, às vezes têm umas que relatam assim, que o marido não quer ficar. Então realmente foi uma proposta muito boa. (Entrevista com educadora em núcleo do Projovem Urbano, Feira de Santana)

Os depoimentos das jovens sobre as razões do abandono dos estudos tendem ao monofônico, destacando-se questões de gênero, como gravidez e proibição do marido, ou encargos com o doméstico:

- Até a 7ạ série foi tranquilo, depois da 8a já faltava muito, não queria mais saber de estudar, eu acabei parando, foi onde eu acabei casando e engravidando do meu filho, daí fiquei cinco anos parada, voltei em 2013, foi em 2013 que começou o Projovem. Os professores foram lá e acabei vindo, eu estava desempregada na época, quando me falaram do dinheiro foi uma ótima... O Projovem foi um ótimo incentivo. Mas na verdade eu vim por causa do dinheiro, depois de algum tempo que eu acabei mudando a cabeça, graças ao Projovem [...] o Projovem é diferente dos outros ensinos. Fui até o 8‥ 
- Eu parei um ano [...] aí por umas influências, aí voltei, deixei [...] de lado, voltei, ai engravidei do meu menino, ai eu parei, voltei agora, está indo muito bem [...] porque pode trazer eles, porque tem escola que não pode levar, bom que pode trazer, tem com que ficar, tem com quem a gente confia, né? O bom é isso, que a gente pode trazer. Quando eu comecei no Projovem estava casada, estava namorando, a gente foi morar junto, daí começou uma frescura, depois fiquei um tempo sem vir na escola por causa disso, ele não queria que eu estudasse nem que eu trabalhasse, a gente acabou separando por causa disso, que ele falou pra mim escolher entre a escola e ele, eu escolhi estudar, porque ninguém vai garantir o meu futuro se um dia a gente chegar a se separar, e uma coisa que eu sempre [...] uma pessoa que não quer que a pessoa estude e não vai pra frente ela não te ama, ela não quer saber [...] desde o começo no Projovem [...] fiquei um bom tempo sem vir por causa dele. Eu não estou mais casada. Tive que separar, ele não aceitava. [Separei] por causa da escola, porque ele mandou eu escolher entre a escola ou ele, eu escolhi estudar.

- [...] na $8^{a}$ série [...] ai começou as más companhias, ai eu parei, ai veio esse negócio do Projovem [...] ai eu comecei a fazer, ai eu tive a minha menina, ai eu parei de vir, ai eu tive [...] uma atrás da outra, tive o bebê [...] (Diálogo em grupo focal com jovens em núcleo do Projovem Urbano, Campo Grande)

O Projovem Urbano com uma Sala de Acolhimento é mencionado, espontaneamente, nas narrativas das jovens sobre suas trajetórias, como estímulo para alterar caminhos:

Quando minha filha completou um ano eu voltei a estudar, ai depois eu logo me separei e tive que começar a trabalhar em dois empregos, eu trabalhava à noite de garçonete e de manhã de cozinheira, aí à noite eu deixei os meus estudos e parei de estudar. Depois logo em seguida eu engravidei de novo, aí não tinha como mais também, eu voltei a estudar quando o meu filho estava de quatro para cinco meses aqui no Projovem. Eu comecei a trazer ele. Fiquei feliz quando me falaram que podia trazer ele, ele era bem novinho e eu comecei a trazer ele pra cá, e agora vou terminar. (Grupo focal com mulheres jovens mães em núcleo do Projovem Urbano, Belém)

Além de possibilitarem que jovens mães possam estudar porque tem quem cuide de seus filhos, as Salas, segundo vários relatos, também aparecem como alternativa diante da desobediência a imposições patriarcais e proibição do marido ou companheiro em relação ao estudo, contribuindo, assim, para elevar a autoestima: 
- Eu parei porque eu me casei. O marido não me deixava sair pra lugar nenhum, se eu tivesse que trabalhar eu tinha que trabalhar em casa, e às vezes eu nem trabalhei em casa e ele não deixava, fiquei nisso ai enrolando por sete anos, até que no ano passado o pessoal do Projovem me bateu na porta de casa, eu falei eu vou em busca do que eu deixei de lado. [o marido] Graças a Deus morreu. [Gargalhadas]. (Grupo focal com mulheres jovens em núcleo do Projovem Urbano, Belém)

- Eu tenho muita dificuldade eu tenho três crianças, no começo do programa o meu marido me apoiava bastante, agora não, não sei que diacho que aconteceu que ele, às vezes ele fala, "hoje tu não vai", e às vezes eu não venho mesmo, mas tem dia que eu venho e falo: eu vou porque é pra mim e para os meus filhos, eu quero conseguir uma coisa melhor pra mim.

- Antes eu era muito burra demais, é verdade, quando eu tinha alguma entrevista né, faltava a fala. Aí as aulas de panificação elas dão mais ou menos como se comportar em entrevista de emprego, e também esse curso que a gente tá fazendo agora ajuda. Ele me achava burra, venho mesmo ele queira ou não. Não sou burra, nada! (Diálogo em grupo focal com mulheres jovens em núcleo do Projovem Urbano, Belém)

- O meu marido não deixava eu estudar.

- O meu também não.

- O meu primeiro marido ele não deixava por ciúme.

- Eu tinha 16 anos mas saí.

- O meu não deixava por ciúmes, e eu tinha dois meninos.

- É agora a gente trazendo o filho, ele deixa.

- O meu eu fui morar com ele, eu descobri que eu estava grávida ele não quis que eu estudasse mais, ai quando eu tive a do meio começou as brigas tudinho porque eu queria começa a estudar ele não deixava. Ai eu tive a última, quando eu tive a última eu separei dele por isso que consegui voltar a estudar.

- Ele dizia "você não vai", ai o povo chegava lá em casa para fazer a matrícula, ele dizia "você não vai", ai eu não tinha como ir.

- Ele falava, "uma mulher veia já quase coroa querendo estudar". (Diálogo em grupo focal com jovens em núcleo do Projovem Urbano, João Pessoa)

Tanto as mulheres como os homens indicam que escolhas foram feitas, sendo marcas geracionais, do ser jovem, dar prioridade por viver o momento, curtir amigos e namoro, o que excluiria tempo para estudos: "Eu estudei até o sexto ano [...] porque é adolescente e tal, aí acaba querendo namorar, desistindo da escola, casei cedo”. 
Também evidenciaram-se marcas de classe, uma vez que os jovens mencionam em suas trajetórias as possibilidades de combinações. Os depoimentos sugerem que escolhas são impostas, ou se estuda ou se trabalha, assim como ou se estuda ou se diverte. ${ }^{5}$ Há ilustrações de que trajetórias são reaprumadas, principalmente quando oportunidades são apresentadas, como o Projovem Urbano:

\begin{abstract}
Eu parei assim, porque o meu pai separou da minha mãe muito cedo então a gente era muito pequenininho e a gente começou a trabalhar que a minha mãe não tinha condição de dar, a minha situação não, dos meus irmãos também era assim, tinha que trabalhar e estudar então em casa ela queria que eles trabalhasse e estudassem então eu ficava de fresco que eu morava pra cá, a minha mãe não tinha dinheiro do ônibus eu trabalhava na pedreira, o que eu fazia, eu saia 5 horas da manhã e ia trabalhar quando eu saia do meu trabalho eu ia pra escola, ai da escola eu tinha que andar de Miranda até Beira de volta no caminho, gastava uma passagem de ônibus porque a minha mãe não tinha pra me dar no outro dia, então ficou difícil, teve a situação que foi, foi e ai eu parei porque não tinha como eu estudar quando eu trabalhava né e morava aqui, não tinha como. (Grupo focal com jovens em núcleo do Projovem Urbano, Curitiba)
\end{abstract}

É por motivo de trabalho eu só tinha uma filha. Ai eu tinha que começar a trabalhar porque eu deixei o pai da minha filha. (Grupo focal com mulheres jovens em núcleo do Projovem Urbano, Belém)

Note-se que se o filho e a gravidez contribuíram, em muitos casos, para que as jovens deixassem de estudar, é precisamente pelo filho, pelo exemplo que podem dar a ele, que elas voltam à escola:

Porque o Projovem dá uma oportunidade para a gente e porque
aqui tem onde deixar as crianças. Porque em outros colégios a
gente não tem com quem deixar os nossos filhos. Minha mãe não
fica com meus filhos. Minha sogra também não fica. Quem tem que
se virar sou eu e meu esposo. Meu esposo às vezes chega muito
tarde do trabalho e não dá né eu sozinha. Então aqui pelo menos
aqui tem a salinha que deixa eles, então está tudo certo. A melhor
coisa que aconteceu aqui para a gente né, porque senão nem uma
de nós podia estudar né. (Grupo focal com jovens em núcleo do
Projovem Urbano, Nova Iguaçu) Eu casei com 16 anos, e aí eu engravidei e aí já não tinha mais como voltar à escola, ou você trabalha e cuida do seu filho ou você vai para a escola e aí, como fazer para se alimentar? Daí me separei e fui para mulheres em combinar escolhas, ver Araújo e Scalon (2005). 
casa dos meus pais e comecei a trabalhar, a focar no trabalho, e dai passou o ano, passando do tempo e com 23 anos eu voltei a estudar novamente. Dai desisti aí voltei de novo até que apareceu o Projovem. Que até mesmo a X foi até a minha casa fazer a representação do Projovem, a representação do que era o Projovem, foi o que me incentivou a vir estudar e estou aqui até hoje terminando. (Grupo focal com jovens em núcleo do Projovem Urbano, Curitiba)

\section{AS MÚLTIPLAS NUANCES DO CUIDADO E DO ACOLHIMENTO NAS SALAS}

Entre os vários entrevistados, independentemente do seu papel no Programa Projovem Urbano, são comuns as expressões sobre a importância das Salas de Acolhimento. As educadoras se consideram partícipes de um programa social relevante para os jovens, o que contribui para se sentirem gratificadas com o que fazem: "Ainda tem muita evasão, mas seria maior [sem as Salas] porque elas [as crianças] não teriam com quem ficar. Ficavam na rua e na violência geral nesse país, não teria condições, não”. Elas se definem, com orgulho, como educadoras e, subliminarmente, indicam que o Projovem Urbano é um programa de uma economia do cuidar.

A operacionalização do cuidar das crianças em uma Sala toma sentidos diferenciados, dependendo muito da criatividade e vocabulário de motivos de cada educadora. Algumas são mais preocupadas com a proteção, outras com as atividades a serem desenvolvidas com as crianças e há até as que, ainda que com boas intenções, resvalam por educação tutelada, inclusive com ênfase em princípios de determinado credo. Nos quadros a seguir, são ilustradas diferentes operacionalizações simbólicas, no nível das Salas, do cuidar, considerando observação participante e entrevistas.

\section{QUADRO 1}

\section{FORMAS DE CUIDAR - CRIANÇAS ATIVAS, ESTÍMULO À CRIATIVIDADE}

Em uma sala as crianças com tinta guache, caixas de papelão e cola colorida armavam,
algumas em grupo, outras separadas, castelos e "telefones" de papelão, e pintavam.
Segundo a educadora: "Não tem uma fórmula, a gente joga na mão delas [materiais] para
elas criarem, aí elas vão criando. A partir disso a gente vai dando opinião, vai influenciando,
pequenas influências, mas $80 \%$ é por conta delas. Mas a gente se surpreende, surge muita
coisa interessante".

\section{QUADRO 2}

\section{FORMAS DE CUIDAR - CRIANÇAS PASSIVAS, MENSAGEM RELIGIOSA}

Chego em uma Sala no meio de uma apresentação de fantoches, as crianças, a maioria entre
quatro e sete anos, sentadas e muito atentas à apresentação. Crianças caladas, pouca inte-
ratividade, não são estimuladas a participar.
A peça enfatiza mensagem religiosa "Jesus protege e ilumina"; "Jesus nos convida a amar
uns aos outros".
A educadora, que manipula os fantoches, pergunta se querem pirulito. Todos respondem
que sim - essa é a única interação.
Em outra Sala, as crianças de sete e oito anos chegam caladas, olham de soslaio, sentam,
pedem lápis e colorem a folha de xerox, com o Bambi pré-moldado. A educadora diz que
amanhã será dia de contar estória. Pedimos para ver o livro de estória: uma bíblia evangélica
ilustrada para crianças.


Mãe 1 - Aqui tinha umas educadoras que nem ligavam, deixavam os pirralhos chorando. Elas ficavam na porta da sala de aula pra [nos] entregar os pirralhos chorando. Houve muita reclamação elas foram demitidas. Ah... é como uma mãe, as crianças adoram ela, não querem nem sair da Sala.

Mãe 1 - O meu fala demais da educadora. É louco por ela, é tia pra cá, tia pra lá, mas depois de quarta-feira não quer vir não, porque um menino... deu uma bolada nele. A educadora está preocupada, ele volta.

Mãe 2 - Ah... agrada muito os meninos. A dela não ficava na sala não, de jeito nenhum, por causa das primeiras educadoras, agora é apaixonada pela tia...

As mães, além de buscarem um lugar para deixar os filhos, preocupam-se com a qualidade do cuidado, enfatizando a proteção. E, de alguma forma, coparticipam da gestão das Salas, supervisionando tal qualidade.

\section{QUADRO 4}

\section{CUIDADO - PROTEÇÃO}

Mãe 1 - A primeira educadora que teve, no início do ano, eu cheguei até a chamar os professores e mostrar. Ela ficava batendo papo no celular.

Mãe 2 - A outra educadora... deixou cair a menina no chão, assim. A menina não andava. Era de sete meses. Dizem que a menina não teve nada na cabeça. Mas como, se a menina bateu a cabeça e não tem nada na cabeça? Ela ficou em observação. Eu quase matava ela.

Em muitos casos, mais do que profissionalismo, espera-se que a educadora se "sacrifique", superando as limitações que encontra, doando algo de si. É a ideia do trânsito entre cuidar proteção, cuidar estimular criatividade e cuidado dádiva. Tais construções se alicerçam em prática de gestão, reconhecendo-se que, na seleção das educadoras, é importante analisar parâmetros formais, como experiência e cursos, mas que, na prática, a "vocação", o "jeito com crianças" e a "sensibilidade” seriam mais relevantes. Ou seja, na seleção, estereótipos de gênero são sutilmente reproduzidos e as mulheres seriam cuidadoras por excelência.

\section{QUADRO 5}

\section{CUIDADO ACOLHIMENTO - CUIDADO VOCAÇÃO - CUIDADO DÁDIVA}

Como coordenadora, eu acho que acima até da qualificação que se tenha, a educadora ideal é aquela que acolhe com carinho e que supera as dificuldades do trabalho de lidar, do cuidar mesmo. Aquela que encontra sempre uma alternativa numa busca do que fazer mesmo sem ter recursos, mesmo sem ter formação.

A orientação que capacita exercer cargos na economia do cuidar, como o de educadora em Sala de Acolhimento, não seria necessariamente algo nato, natural, mas cultivado inclusive por habilidade do trabalhar em equipe, por cooperação: 
educadoras. As mães não gostavam do tratamento que elas davam aqui e chegaram a falar que iriam se reunir para bater nelas. $E$ todas duas eram pedagogas. Uma foi diretora de uma creche, trabalhava com educação infantil, e a outra também recém-formada, com experiência com crianças na igreja, então a gente achou que era a dupla ideal. Mas o tratamento era horrível. Uma educadora só queria dar aula, ela queria que as crianças fossem para Sala de Acolhimento para assistir aula, a outra era muito dura, muito rígida com elas. Então resolvemos tirá-las, demiti-las e chamamos $X$ que era apoio, mas que já ajudava e as mães tinham uma confianca maior nela, ela assumiu como educadora. E Y que era também outro apoio de um outro núcleo e veio a somar $\operatorname{com} X$, porque ela não tinha experiência, ela não é pedagoga, ela é mãe então assim, a gente acreditou que juntando as duas daria uma experiência. E até agora tem dado certo, as mães gostam muito, tem gostado muito dessa dupla, são uma equipe. (Entrevista com coordenadora de formação do Projovem Urbano, João Pessoa)

Sinto falta de palestras e cursos sobre cuidados. Em um ano só tivemos uma palestra sobre esse tema e ficamos [as educadoras] maravilhadas, mas foi só isso. Eu faço o que sei, às vezes consulto a internet, os pequenos se cansam das mesmas brincadeiras, ver TV e estórias. (Entrevista com educadora de uma Sala de Acolhimento, Nova Iguaçu)

A segurança e o cuidado compartidos por educadoras e os responsáveis são positividades destacadas, reconhecendo-se que a modelagem das Salas em relação a creches se singularizaria pela participação dos pais, sua maior vigilância ao tipo de cuidado que recebem seus filhos: "Ele fica brincando aqui eu estou do lado, estou vendo onde ele está. Está mais guardado do que propriamente dentro de casa. Dentro de casa às vezes dá uma fugidinha. E mãe quer sempre os filhos perto”.

A mãe tem com quem compartir os cuidados dos filhos - uma outra mulher, a educadora - e conciliar algo que colabora, em tese, para emancipação - estudar - e as exigências do marido. Insiste-se que a Sala de Acolhimento direta e indiretamente colabora para passos emancipatórios das mulheres, possibilitando que elas voltem a estudar:

- Pra mim assim foi muito bom porque não tenho com quem deixar meu filho. Ai eu imaginava como é que eu vou estudar se eu não posso levar ele? Não vou. Não tem com quem deixar. Meu marido estuda aqui.

- Eu acho assim porque muitas mulheres voltaram a estudar. É um projeto que veio dar certo porque caso contrário como ia deixar essa criança, com quem, pra estudar? Pro homem é até mais fácil. 
Muitas coisas para o homem às vezes é até mais fácil. Pra mulher às vezes tem dificuldade. A mulher mesmo que trabalha fora às vezes tem que chegar e cuidar da criança e tem dificuldade. Pra mulher quando ela chega aqui tem uma pessoa que cuida da criança dela, acho que isso ai é excepcional. (Diálogo em grupo focal com jovens em núcleo do Projovem Urbano, Quixeramobim)

Todas as mães insistem que, se não fossem as Salas de Acolhimento, não teriam permanecido na escola: “Eu já teria saído da escola; eu nem tinha entrado para o Projovem; iria ser difícil; já teria saído há muito tempo; eu não iria estudar; eu não teria condições de continuar o meu estudo; se não tivesse a professora que cuida das crianças não teria nem como estudar".

\section{SENTIDOS DA SALA NA RELAÇÃO MÃE E FILHOS}

$O$ fato de as mães estarem estudando as aproxima de seus filhos, falando uma linguagem comum, como se capta em distintos depoimentos, em diferentes lugares: "Lá em casa ele me ensina e eu ensino ele”; “É igual ela a minha filha ela ficou atrasada e nós estávamos na mesma série também"; "Conversamos bastante hoje ela chegou com o livro e falou 'olha mãe mesma coisa que você estuda eu estou estudando também de inglês'”; "Meu filho chegava com o dever em casa, tinha vezes que meu filho me pedia ajuda aí eu jogava para cima do meu marido, 'ah, vai lá pede ao seu pai'”; "Porque é muito triste você estar em casa e o seu filho chegar com o caderno e te pedir uma informação e você ali como mãe você não poder dar a informação que seu filho está pedindo".

As crianças também exercem pressão sobre as mães, seja quando essas faltam, ou se atrasam para ir à escola: "A minha sempre dizia: 'mãe, você está faltando à aula demais', 'mãe, porque antes você não faltava nada e agora você está faltando?’; “O meu pega no meu pé, 'você não vai tomar banho para ir à escola?' 'Mãe você não disse para eu nunca faltar à aula? A senhora também não falte"; "A minha maior ela fica, 'vamos mãe' e se eu quero faltar ela fala 'não é certo"'.

A discussão também se deu em função da vergonha que as mães sentiam de seus filhos e dos amigos dos filhos por não terem estudos: "Eu tenho vergonha da minha própria filha. Ela já está quase na metade do que eu parei, na sexta. Eu tinha vergonha dela e dos amigos". A vergonha surge nas reuniões quando a professora explica a matéria que está dando e a mãe não consegue colaborar e acompanhar a filha: 


\begin{abstract}
a ela um dever de casa se eu não sei fazer. Ela já foi à escola com dever em branco. Eu fui à escola e falei para a professora eu não sei fazer esse dever e mais de Matemática que eu tenho uma grande dificuldade na matéria que ela está em Matemática eu acho que vai cair na minha prova. No meu caso é vergonha mesmo. (Grupo focal com jovens em núcleo do Projovem Urbano, Rio Branco)
\end{abstract}

\title{
CONSIDERAÇÕES FINAIS
}

Sobre a literatura relacionada à economia do cuidado, destacam Guimarães, Hirata e Sugita (2011, p. 151): "As teorias e os debates sobre o care que datam de ao menos trinta anos no mundo anglo saxônico, em particular nos Estados Unidos (Gilligan [1982] 2008; Tronto [1993] 2009; Moller Okin, [1989] 2008), desenvolveram-se bem mais recentemente na França, apenas nos últimos cinco anos (Paperman \& Laugier, 2005; Molinier Paperman \& Laugier 2009 Garrau \& Goff, 2010), e têm suscitado um interesse crescente na América Latina e na América Central, onde pesquisas vêm sendo realizadas em países como Chile, México, Argentina e Nicarágua. No Brasil, no campo das ciências sociais, ainda são poucas as investigações no tema (Lancman et al., 2007 Batista et al., 2008; Sor 2008; Lima et al., 20082009; Garcia dos Santos \& Georges, 2010; Camarano 2010) e a maior parte das pesquisas, tanto sobre os cuidadores familiares. quanto sobre o cuidado em domicílio, foi produzida nas áreas da geriatria gerontologia, enfermagem e saúde pública. No Japão, os médicos foram também os primeiros a suscita a questão do cuidado que se popularizou, na década de 1990, com o debate em torno do Seguro de Cuidados de Longa Duração' (Kaigo Hoken) introduzido em

2000; desde então, têm se multiplicado os trabalhos no âmbito das ciências sociais japonesas (Ito \& Adachi, 2008: Ochiai, 2009; Mitomi, 2010; Kikuchi, 2010)".

Em alguns casos elas se referem como cuidadoras e, em outros, como educadoras.
Se, como ressaltado em ampla literatura sobre o Projovem Urbano, esse programa se afirma pela orientação por inclusão, justiça social, já o sentido das Salas passa pelo reconhecimento contemporâneo da importância de modelar políticas sociais considerando vivências, trânsitos e combinações entre o privado e o público, assim como as marcas de classe, gênero e territorialidade de tais vivências.

Tal amplitude de referências nos levou a destacar o alcance reflexivo do debate de conceitos como acolhimento e cuidar - entendido como parte de uma economia que se nutre de uma ética pelo outro, pela outra -, para melhor singularizar o público do Projovem Urbano, que mais necessita de Salas de Acolhimento, já que a maioria é composta por mulheres, com pouco ou nenhum respaldo na criação dos filhos por parte dos maridos, que nutrem vontade e garra para estudar, para ter mais autonomia e não mais se submeterem a papéis tradicionais, pautados pela subordinação à casa e ao cônjuge.

Contudo, em que pesem as diferenças do caso analisado, das referências empíricas de boa parte da literatura sobre economia do cuidado com seres humanos (GUIMARAES, 2016; HIRATA; GUIMARAES 2012; TORN, 2008; GUIMARÃES; HIRATA; SUGITA, 2011, entre outros ${ }^{6}$ ), se o foco são as profissionais, ou seja, as mulheres cuidadoras ou educadoras, ${ }^{7}$ o programa de fato contribui para a reprodução de estereótipos de gênero, apostando que voluntariamente as mulheres que o exercem, por serem pessoas que fazem seu trabalho com amor, não necessitam de profissionalização, reciclagem, estímulo para estudar um campo complexo como o da educação infantil, sendo que as Salas se quer se diferenciam tanto das creches como das escolas. Elas mesmo reconhecem que se "viram", mas gostariam de poder se atualizar em relação ao trabalho produzido nesse campo.

Já em relação às mães que estudam, as jovens do Projovem Urbano, outro seria o possível impacto das Salas. O tema dos cuidados de crianças associa-se a mudanças que a família vem passando nas últimas décadas. As formas de investimento de cada membro da família no acompanhamento do desenvolvimento dos filhos pedem reconhecimento da ampliação da participação da mulher no mercado de trabalho 
e dos seus direitos, inclusive o direito de estudar. De fato, as Salas possibilitaram que as mães pudessem voltar a estudar.

Consideram-se as Salas de Acolhimento um tipo de economia do cuidar, que se baseia tanto em qualidades objetivas como em relações sociais e afetivas entre as educadoras, as mães e as crianças.

As Salas de Acolhimento colaboram para desestabilizar a reclusão das mulheres ao plano do doméstico, orientando-se para os cuidados das crianças e permitindo que as mães possam voltar a estudar e se sintam seguras pela proximidade da sua sala de aula com o espaço das crianças. Dessa forma se inova na economia do cuidar, com as mães sentindo que têm alguma participação nessa.

$\mathrm{O}$ apreço das crianças pelo que carinhosamente chamam "a minha salinha” e a "escola da mãe” é sugerido pela observação de que muitas delas insistem em ir para as Salas, o que as leva também a pressionar para que as mães não faltem à escola. Muitas mães declaram que estão estudando e são assíduas para acompanhar e incentivar os filhos. Várias se referem ao sentimento de vergonha por terem abandonado a escola. Tais dados questionam a relação linear entre ter filhos e estudar, já que, se para muitas mulheres a maternidade foi um obstáculo, hoje é um desafio que enfrentam e lhes causa orgulho.

Insistem todos os entrevistados - educadoras e alunos - que, sem as Salas de Acolhimento, a maioria das mães não estaria cursando o Projovem Urbano, inclusive pela vigência de orientação patriarcal que legitima a repressão familiar, o impedimento por parte dos companheiros ou a falta da sua colaboração nos cuidados dos filhos. É quando se evidencia um simbolismo latente das Salas e sua conjugação ao Projovem Urbano, qual seja, o estímulo à emancipação da mulher mãe, como sujeito de vontades e que pode ser mãe e estudante.

A ética de cuidado das mulheres com seus filhos coloca para elas obstáculos não enfrentados comumente pelos homens, ou seja, a conciliação da proteção e acompanhamento dos filhos e os direitos de estudar e de emprego. Isso ilustra a importância também de chamada no campo de direitos humanos das mulheres: o de uma educação sensível ao status de mãe dessas jovens. Mas, insiste-se, se as mães alunas no Projovem Urbano, com as Salas, puderam desestabilizar, mesmo que por um período limitado, “destinos” de gênero, sua exclusão do mundo dos estudos, já em se tratando das mulheres cuidadoras ou educadoras, o Programa das Salas deixa a desejar e, de alguma forma, se oportuniza por reproduzir a ideia essencialista de que as mulheres seriam aptas para o cuidar e não necessitariam de melhor profissionalização. 


\section{REFERÊNCIAS}

ARAUJO, Clara; SCALON, Celi. Percepções e atitudes de mulheres e homens sobre a conciliação entre família e trabalho pago no Brasil. In: ARAUJO, Clara; SCALON, Celi (Org.). Gênero, família e trabalho no Brasil. Rio de Janeiro: FGV, 2005. cap. 1, p. 15-77.

BRASIL. Decreto n. 6.629, de 04 de novembro de 2008. Regulamenta o Programa Nacional de Inclusão de Jovens - Projovem, instituído pela Lei n. 11.129, de 30 de junho de 2005, e regido pela Lei n. 11.692, de 10 de junho de 2008, e dá outras providências. Brasília, DF: Casa Civil, 2008a.

BRASIL. Decreto n. 7.649, de 21 de dezembro de 2011. Altera o Decreto n. 6.629, de 04 de novembro de 2008, e dá outras providências. Brasília, DF: Casa Civil, 2011a.

BRASIL. Lei n. 11.692, de 10 de junho de 2008. Dispõe sobre o Programa Nacional de Inclusão de Jovens - Projovem... Brasília, DF: Casa Civil, 2008b.

BRASIL. Ministério da Educação. Nota Técnica n. 001. Brasília, DF: MEC/Secadi, 2012a.

BRASIL. Ministério da Educação. Projovem Urbano 2012. Brasília, DF: MEC/Secadi, 2012b. Disponível em: <http://slideplayer.com.br/slide/53758/> . Acesso em: 2 fev. 2015.

BRASIL. Ministério da Educação. Resolução CD/FNDE n. 60, de 09 de novembro de 2011. Brasília, DF: MEC/FNDE, 2011b.

BRASIL. Ministério da Educação. Resolução n. 54, de 21 de novembro de 2012. Estabelece os critérios e as normas para a transferência automática de recursos financeiros aos estados, ao Distrito Federal e aos municípios com cem mil ou mais habitantes, para o desenvolvimento de ações do Programa Nacional de Inclusão de Jovens - Projovem Urbano, para entrada de estudantes em 2013. Brasília, DF: MEC, 2012. Disponível em: <http://www2.transparencia.pe.gov.br/c/ document_library/get_file?p_1_id=4849910\&folderId=4844473\&name=DLFE-34320.pdf $>$. Acesso em: 20 jan. 2015.

CASTRO, Mary Garcia; CARVALHO, Ana Maria Almeida; MOREIRA, Lucia Vaz de Campos (Org.). Dinâmica familiar do cuidado: afetos, imaginário e envolvimento dos pais na atenção aos filhos. Salvador: Edufba, 2012.

DUARTE, Marisa Ribeiro Teixeira. Palavras de jovens sobre o Projovem: estudos com egressos e a formação de pesquisadores em avaliação de programas educacionais. Belo Horizonte: Escritório de História, 2009.

FIGUEIREDO, Luiz Claudio Mendonça. As diversas faces do cuidar: novos ensaios de psicanálise contemporânea. 1. ed. São Paulo: Escuta, 2009.

GIDDENS, Anthony. A transformação da intimidade: sexo, amor e erotismo nas sociedades modernas. São Paulo: Editora Unesp, 1993.

GONÇALVES DA FONSECA, Rosilaine. Como estudar se não tenho com quem deixar meus filhos? Um estudo sobre as salas de acolhimento do Projovem Urbano. 2014. 163 f. Dissertação (Mestrado em Educação) - Universidade Federal do Estado do Rio de Janeiro, Rio de Janeiro, 2014.

GUIMARAES, Nadya Araújo. Casa e mercado, amor e trabalho, natureza e profissão. Controvérsias sobre o processo de mercantilização do trabalho de cuidar. Cadernos Pagu, Campinas, n. 46, p. 59-77, jan./abr. 2016.

GUIMARAES, Nadya Araujo; HIRATA, Helena; SUGITA, Kurumi. Cuidado e cuidadoras: o trabalho de care no Brasil, França e Japão. Sociologia \& Antropologia, Rio de Janeiro, v. 1, n. 1, p. 151-180, jul. 2011. Disponível em: </C:/cuidado\%20e\%20genero/8-ano1v1_artigo_nadyaguimaraes-helena-hirata-kurumi-sugita.pdf>. Acesso em: 2 nov. 2016.

HIRATA, Helena. Gênero, classe e raça: interseccionalidade e consubstancialidade das relações sociais. Tempos Sociais: Revista de Sociologia da USP, São Paulo, v. 26, n. 1, 2014. Disponível em: <http://dx.doi.org/10.1590/S0103-20702014000100005>. Acesso em: 18 out. 2016.

HIRATA, Helena; GUIMARAES, Nadya Araújo. Cuidado e cuidadoras: as várias faces do trabalho do care. São Paulo: Atlas, 2012.

ILLOUZ, Eva. Saving the modern soul: therapy, emotions and the culture of self-help. Berkeley and Los Angeles, California: University of California Press, 2008. 
JELIN, Elizabeth. Pan y afectos: la transformación de las familias. Buenos Aires: Fondo de Cultura Econômica de Argentina, 2006.

KISHIMOTO, Tizuko Mochida. Brinquedos e materiais pedagógicos nas escolas infantis. Educação e Pesquisa, São Paulo, v. 27, n. 2, p. 229-245, jul./dez. 2001.

LAPA SANTO, Tatiane Rabelo; PANIZZOLO, Claudia. O brincar, o brinquedo e a brinquedoteca: um balanço acerca da presença/ausência da concepção infầncia/criança na produção acadêmica. Horizontes, Bragança Paulista, v. 31, n. 2, p. 77-88, jul./dez. 2013. Disponível em: <http:/ revistahorizontes.usf.edu.br/ojs/index.php/horizontes/article/viewFile/9/9>. Acesso em: 10 fev. 2015.

LORENZONI, Ionice. Programa permitirá a jovens concluir o ensino fundamental. Maio de 2013. Disponível em: <Portal.mec.gov.br/index.php?option= com_content\&view= article\&id= 18700 :programa-permitira-a-jovens-concluir-o-ensino-fundamental-\&catid=211\&Itemid=86>. Acesso em: 26 jan. 2015.

MEYER, Dagmar Elisabeth Estermann. Cuidado e diferença: da integralidade à fragmentação do ser. Revista Gaúcha de Enfermagem, Porto Alegre, v. 22, n. 2, p. 21-30, jul. 2001. Disponível em: <http://hdl.handle.net/10183/23471>. Acesso em: 30 out. 2016.

MORAES, Maria Lygia Quartim de. A estrutura contemporânea da família. In: COMPARATO, Maria Cecília Mazzilli; MONTEIRO, Denise de Souza Feliciano (Org.). A criança na contemporaneidade e a psicanálise: família e sociedade: diálogos interdisciplinares. São Paulo: Casa do Psicólogo, 2001. v. 1, p. 17-25.

NOVAES, Regina Célia Reyes; CARA, Daniel; MOREIRA, Danilo. Palavras finais. In: BRASIL. Conselho Nacional da Juventude. Política Nacional de Juventude: diretrizes e perspectivas. São Paulo: Conselho Nacional de Juventude; Fundação Friedrich Ebert, 2006. p. 130-133.

SAMARA, Eni de Mesquita. O que mudou na família brasileira? Da colônia à atualidade. Psicologia USP, São Paulo, v. 13, n. 2, p. 27-48, 2002.

SOARES, Ângelo. As emoções do care. In: HIRATA, Helena; GUIMARAES, Nadya Araújo. Cuidado e cuidadoras: as várias faces do trabalho do care. São Paulo: Atlas, 2012. p. 44-60.

TORN, Teresa. El trabajo y el cuidado: cuestiones teóricometodológicas desde la perspectiva de género. Empiria: Revista de Metodología de Ciencias Sociales, n. 15, p. 53-73, enero/jun. 2008.

YIN, Robert. Estudo de caso: planejamento e métodos. 4. ed. Porto Alegre: Bookman, 2010.

ZELIZER, Viviana. A economia do care. In: HIRATA, Helena; GUIMARAES, Nadya Araújo. Cuidado e cuidadoras: as várias faces do trabalho do care. São Paulo: Atlas, 2012. p. 15-28.

\section{MARY GARCIA CASTRO}

Professora da Universidade Católica de Salvador, Salvador, Bahia, Brasil; pesquisadora da Faculdade Latino-Americana de Ciências Sociais - Flacso-Brasil e do Conselho Nacional de Desenvolvimento Científico e Tecnológico - CNPq -, Brasília, Distrito Federal, Brasil castromg@uol.com.br

MIRIAM ABRAMOVAY

Coordenadora da Área de Pesquisas sobre Juventude da Faculdade Latino-Americana de Ciências Sociais - Flacso-Brasil mabramovay@gmail.com 